\title{
A New Study to Suppress Mutual-Coupling between Waveguide Slot Array Antennas based on Metasurface Bulkhead for MIMO Systems
}

\author{
Mohammad Alibakhshikenari ${ }^{1}$, Bal Singh Virdee ${ }^{2}$, Mohsen Khalily ${ }^{3}$, Chan Hwang See ${ }^{4}$, Raed Abd-Alhameed ${ }^{5}$, \\ Francisco Falcone ${ }^{6}$, and Ernesto Limiti ${ }^{1}$ \\ ${ }^{1}$ Electronics Engineering Department, University of Rome "Tor Vergata", Via del Politecnico 1, 00133 Roma, ITALY \\ ${ }^{2}$ London Metropolitan University, Center for Communications Technology, \\ School of Computing and Digital Media, London N7 8DB, UK \\ ${ }^{3} 5 \mathrm{G}$ innovation Center (5GIC), Institute for Communication Systems (ICS), University of Surrey, Guildford, GU2 7XH, U.K \\ ${ }^{4}$ School of Engineering, University of Bolton, Bolton, BL3 5AB, U.K. \\ ${ }^{5}$ School of Electrical Engineering and Computer Science, University of Bradford, Bradford, BD7 1DP, UK \\ ${ }^{6}$ Electrical and Electronic Engineering Department, Public University of Navarre, 31006 Pamplona, SPAIN \\ \{alibakhshikenari, limiti\}@ing.uniroma2.it, b.virdee@londonmet.ac.uk,m.khalily@surrey.ac.uk, c.see@bolton.ac.uk, \\ r.a.a.abd@bradford.ac.uk, francisco.falcone@unavarra.es
}

\begin{abstract}
In this paper, a new method is proposed to reduce mutual coupling between waveguide slot array (WSA) antennas based on metasurface technology. This is achieved by placing a metasurface bulkhead between the two WSA antennas. Performance of the dual-waveguide antenna structure is shown to substantially enhance when compared against an identical reference WSA antenna with no metasurface. WSA antennas used in the study has dimensions $40 \times 20 \times 5 \mathrm{~mm}^{3}$ and operates over 1.7-3.66 GHz, which corresponds to a fractional bandwidth of $73.13 \%$. The average isolation of the reference WSA antennas is $\mathbf{- 2 0} \mathbf{~ d B}$; however, with a metasurface bulkhead the isolation is shown to increase to $\mathbf{- 3 6 . 5} \mathbf{d B}$. In addition, the bandwidth extends by $\sim 10 \%$, and the gain improves by $14.66 \%$. The proposed method is should find application in MIMO systems where high isolation between neighbouring radiation elements is required to improve the antenna characteristics, and mimimise array phase errors, which is necessary to enhance the system performance.
\end{abstract}

Keywords: Suppression mutual coupling, metamaterial bulkhead, waveguide slot array antennas, multiple-input multiple-output (MIMO) systems, array structures.

\section{INTRODUCTION}

Waveguide slot array (WSA) antennas offer desirable features that include low-loss, moderate cost, and high power-handling capability [1]. However, the main drawback of WSA structure is the mutual coupling between the slot antennas, which degrades the antenna gain, bandwidth and distorts the radiation pattern. For application of WSA antennas in next generation MIMO systems requires a high degree of isolation and low envelope correlation coefficient [2]. Various approaches have been used to reduce mutual coupling, examples include using (i) a coplanar strip wall between two antennas has been reported in [3]; (ii) a metasurface corrugations [4]; and a frequency selective surface in [5]. However, these techniques degrade the antenna radiation pattern. This is due to the fact that a frequency selective surface wall or a coplanar strip wall is not matched. As a result, the radiation pattern is distorted due to reflected waves from the embedded wall between the antennas.

In this paper a new approached is presented to enhance insolation between WSA antennas. The method essentially involves placeing a metasurface between the waveguide slot antennas. The proposed technique is shown to improve isolation by $16.5 \mathrm{~dB}$ and enhance the gain and operational bandwidth by $14.66 \%$ and $\sim 10 \%$, respectively. The proposed technique is simple to implement and effective.

\section{MetasurfaCe BULKHEAD}

To enhance isolation between the radiation elements of waveguide slot array antennas a metasurface was placed between the WSA structure. Dimensions of each slot are $1 \times 1 \times 0.55 \mathrm{~mm}^{3}$. To demonstrates the effectiveness of the proposed approach two WSA antennas were employed, where one of them was a used as a reference antenna with no metasurface and the other was WSA antennas with metasurface. The metasurface is constituted from a dielectric substrate where the outer metallisation surface is embedded with a $2 \times 6$ slot array. Dimensions of each slot are $1 \times 0.5 \times 0.05 \mathrm{~mm}^{3}$, which were obtained through simulation analysis. In the structure the slot arrays essentially play the role of series left-handed capacitance $\left(\mathrm{C}_{\mathrm{L}}\right)$, and the structure induces loops in the surface currents, resulting in series right-handed inductance $\left(\mathrm{L}_{R}\right)$. The shunt right-handed capacitance $\left(C_{R}\right)$ is created by the gap between the surface of the waveguide and groundplane. Proof-of-concept in this study is evaluated using 3D full-wave commercially available electromagnetic tool. The proposed technique is simply to implement in practice.

The experimental two WSA antennas were constructed using Rogers RT5880 lossy substrate with dielectric constant of 2.2 and $\tan \delta=0.0009$. The reference waveguides, shown in Fig. 1(a), were isolated from each 
other with a dielectric bulkhead of dimensions $40 \times 4 \times 5$ $\mathrm{mm}^{3}$. Total dimensions of the WSA antennas are $40 \times 20 \times 5$ $\mathrm{mm}^{3}$.

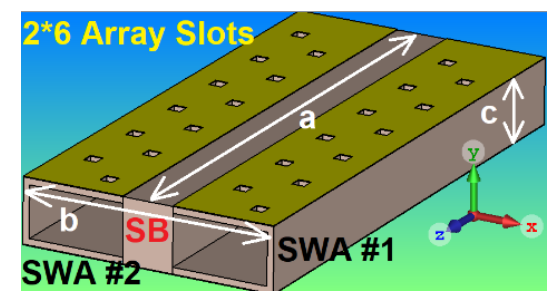

(a) WSA antennas with simple bulkhead (SB) of RT5880.
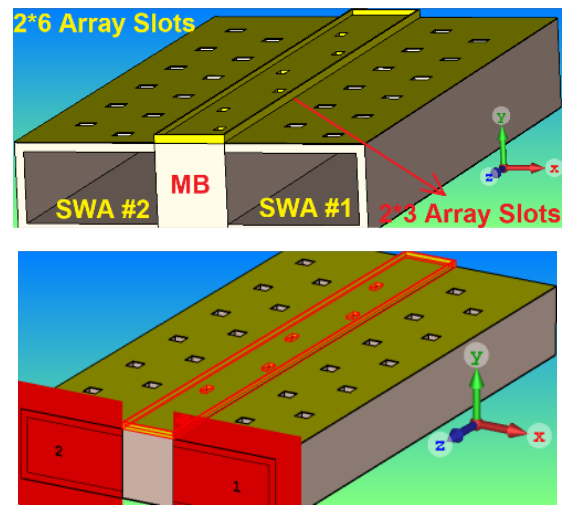

(b) WSA antennas with metasurface bulkhead (MB)

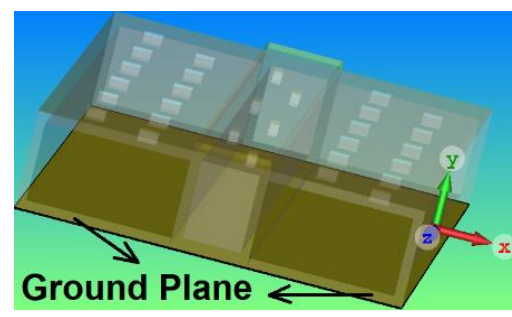

(c) 3-D view of the WSA with MB

Fig.1. Configuration of the reference and proposed waveguide slot array (WSA).

S-parameter performance of the reference WSA antennas is shown in Fig. 2 and the salient features summarized in Table I. This structure operates over L- and S-bands covering a frequency from $1.7 \mathrm{GHz}$ to $3.66 \mathrm{GHz}$. Minimum, average, and maximum isolation level between the radiation elements without metasurface are $-13.5 \mathrm{~dB}$, $20 \mathrm{~dB}$, and $-27 \mathrm{~dB}$, respectively.

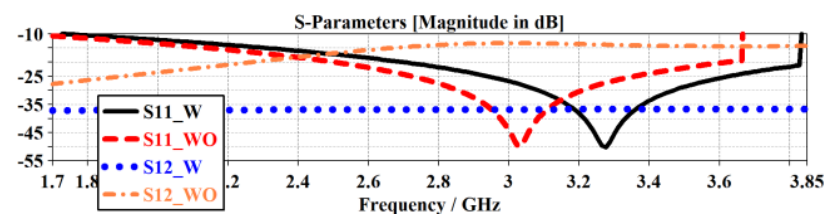

Fig.2. Reflection and transmission coefficients of the reference and proposed WSA antennas without (WO) and with (W) metasurface bulkhead.

To reduce the mutual coupling between the two WSA antennas a metasurface bulkhead was applied, as shown in Fig. 1(b). Reflection and transition coefficient response of the structure is shown in Fig. 2 and the results are summarised in Table I. With metasurface bulkhead (MB) the antennas cover a frequency range from $1.7 \mathrm{GHz}$ to 3.85 $\mathrm{GHz}$, and the frequency range is extended by $190 \mathrm{MHz}$ with no change in dimensions. For $\left|S_{11}\right| \leq-10 \mathrm{~dB}$, the minimum, average, and maximum isolation levels obtained with $\mathrm{MB}$ are $-36 \mathrm{~dB},-36.5 \mathrm{~dB}$, and $-37 \mathrm{~dB}$, respectively.

TABLE I. S-PARAMETER PERFORMANCE OF THE REFERENCE AND PROPOSED WSA WITH SB AND MB

\begin{tabular}{|c|c|}
\hline \multirow{2}{*}{$\left|S_{11} \leq-10 \mathrm{~dB}\right|$} & $\begin{array}{c}\text { with } \mathrm{SB}: 1.70-3.66 \mathrm{GHz} \\
(\Delta f: 1.96 \mathrm{GHz} \rightarrow 73.13 \% \mathrm{FBW})\end{array}$ \\
\cline { 2 - 2 } & $\begin{array}{c}\text { with } \mathrm{MB}: 1.70-3.85 \mathrm{GHz} \\
(\Delta f: 2.15 \mathrm{GHz} \rightarrow 77.47 \% \mathrm{FBW})\end{array}$ \\
\hline \multirow{2}{*}{ Minimum Isolation } & without metasurface: $-13.5 \mathrm{~dB}$ \\
\cline { 2 - 2 } & with metasurface: $-36 \mathrm{~dB}$ \\
\hline \multirow{2}{*}{ Average Isolation } & without metasurface: $-20 \mathrm{~dB}$ \\
\cline { 2 - 2 } Maximum Isolation & with metasurface: $-36.5 \mathrm{~dB}$ \\
\cline { 2 - 2 } & without metasurface: $-27 \mathrm{~dB}$ \\
\hline \multirow{2}{*}{ with metasurface: $-37 \mathrm{~dB}$} \\
\hline
\end{tabular}

\begin{tabular}{|c|c|}
\hline ISOLATION IMPROVEMENT WITH METASURFACE \\
\hline Minimum & $10 \mathrm{~dB}$ \\
\hline Average & $16.5 \mathrm{~dB}$ \\
\hline Maximum & $22.5 \mathrm{~dB}$ \\
\hline
\end{tabular}

Surface current distribution over the reference and proposed WSA antennas without and with metasurface bulkhead at $3.27 \mathrm{GHz}$ is shown in Fig. 3. Plots are shown when the waveguide is excited from each end. The co- and cross-polarized radiation patterns of the reference and proposed WSA antennas at $2.4 \mathrm{GHz}$ and $3.27 \mathrm{GHz}$ are shown in Fig.4. The structure has a bidirectional radiation pattern. It is evident that after applying the metasurface bulkhead the radiation patterns remain virtually the same. Gain of reference WSA antennas, shown in Fig. 5, varies from $4.5 \mathrm{dBi}$ to $7.5 \mathrm{dBi}$, ut with $\mathrm{MB}$ the gain variation improves from $5.75 \mathrm{dBi}$ to $8.6 \mathrm{dBi}$. These results show with MB the gain improvement variation is $27.77 \%$ to $14.66 \%$ over the specified frequency range.
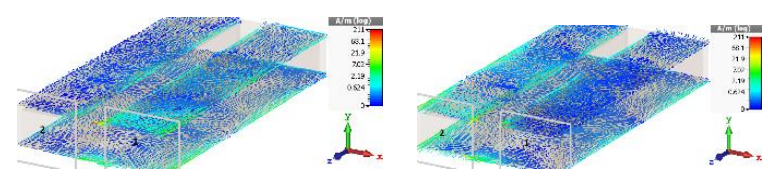

(a) Without metasurface bulkhead
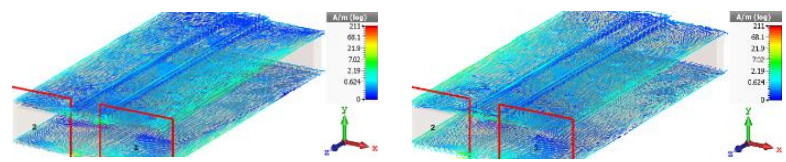

(b) With metasurface bulkhead

Fig.3. Surface current distribution over the reference and proposed WSA antennas at $3.27 \mathrm{GHz}$. Left side shows that port \#1 excited and port \#2 has matched to $50 \Omega$, \& the right side illustrates that port\#2 excited and port \#1 has matched to $50 \Omega$.

The proposed technique is compared with other recent mutual coupling reduction techniques in Table II. The results show that the proposed array antenna operates over a wide bandwidth of more than $2 \mathrm{GHz}$ from 1.7-3.85 GHz 
(77.47\% fractional bandwidth) to support part of L- and Sbands. The results also reveal with metasurface bulkhead a higher isolation is obtained between WSA antennas, and the radiation pattern remains intact. The proposed method is simple to implement, which can be applied retrospectively to existing planar array antennas.

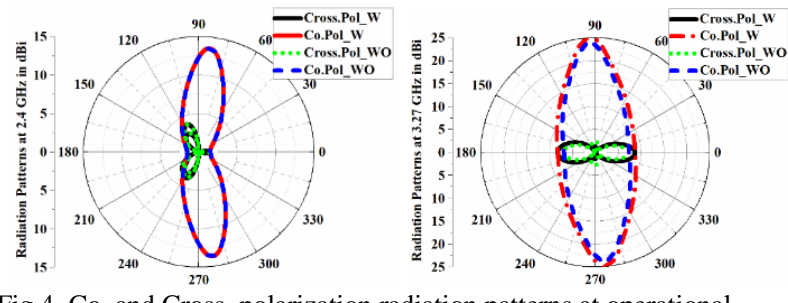

Fig.4. Co. and Cross. polarization radiation patterns at operational frequencies for both cases with no (WO) and with (W) MB.

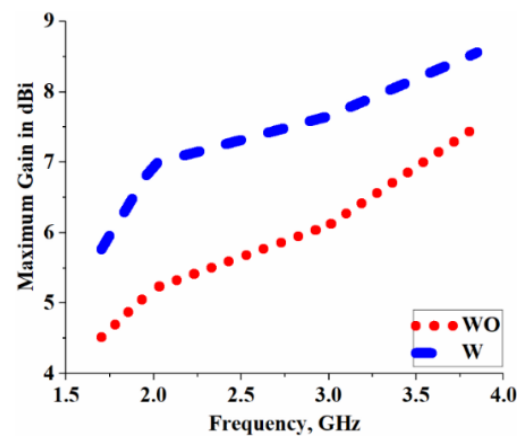

Fig.5. Maximum gain response versus frequency for reference and proposed WSA without (WO) and with (W) metasurface bulkhead.

\section{TABLE II. PROPOSED ARRAY ANTENNA CHARACTERISTICS} COMPARED WITH RECENT WORKS

\begin{tabular}{|c|c|c|c|c|}
\hline Ref. & Method & $\begin{array}{c}\text { Max. isolation } \\
\text { improvement }\end{array}$ & BW & $\begin{array}{c}\text { Rad. pattern } \\
\text { deterioration }\end{array}$ \\
\hline$[6]$ & EBG & $4 \mathrm{~dB}$ & Narrow & Yes \\
\hline$[7]$ & UC-EBG & $10 \mathrm{~dB}$ & Narrow & Yes \\
\hline$[8]$ & Compact EBG & $17 \mathrm{~dB}$ & Narrow & Yes \\
\hline$[9]$ & DGS & $17.43 \mathrm{~dB}$ & Narrow & Yes \\
\hline$[10]$ & U-Shaped Resonator & $10 \mathrm{~dB}$ & Narrow & Yes \\
\hline$[11]$ & $\begin{array}{c}\text { Slotted Meander } \\
\text { Line Resonator }\end{array}$ & $16 \mathrm{~dB}$ & Narrow & Yes \\
\hline$[12]$ & I-Shaped Resonator & $30 \mathrm{~dB}$ & Narrow & Yes \\
\hline$[13]$ & Slot in Ground plane & $40 \mathrm{~dB}$ & Narrow & Yes \\
\hline$[14]$ & SCSRR & $10 \mathrm{~dB}$ & Narrow & Yes \\
\hline$[15]$ & SCSSRR & $14.6 \mathrm{~dB}$ & Narrow & Yes \\
\hline$[16]$ & W/g MTM & $20 \mathrm{~dB}$ & Narrow & No \\
\hline$[17]$ & W/g MTM & $18 \mathrm{~dB}$ & Narrow & No \\
\hline$[18]$ & $\begin{array}{c}\text { Meander Line } \\
\text { Resonator }\end{array}$ & $10 \mathrm{~dB}$ & Narrow & No \\
\hline$[19]$ & Fractal load with DGS & $16 \mathrm{~dB}$ & Narrow & No \\
\hline $\begin{array}{c}\text { This } \\
\text { work }\end{array}$ & Metasurface & $\mathbf{2 2 . 5 ~ d B}$ & Wide & No \\
\hline
\end{tabular}

\section{CONCLUSION}

An effective technique is demonstrated to substantially suppress unwanted coupling between radiation elements in waveguide slot array antennas. This is based on inserted a metasurface bulkhead between the slot array. Average improvement in isolation over the operating band of the antenna is $16.5 \mathrm{~dB}$. With the proposed technique the frequency bandwidth is extended by $190 \mathrm{MHz}$ and the radiation gain is enhanced by $14.66 \%$. This technique is simple to implement and is proposed for MIMO systems.

\section{REFERENCES}

[1] S. R. Rengarajan, M. S. Zawadzki, and R. E. Hodges, "Design, Analysis, and Development of a Large Ka-Band Slot Array for Digital Beam-Forming Application," IEEE Transactions on Antennas and Propagation, AP-57, 10, October 2009, pp. 3103-3109.

[2] J. R. Costa, E. B. Lima, C. R. Medeiros, and C. A. Fernandes, "Evaluation of a new wideband slot array for MIMO performance enhancement in indoor WLANs," IEEE Trans. Antennas Propag., vol. 59, no. 4, pp. 1200-1206, Apr. 2011.

[3] H. Qi, L. Liu, X. Yin, H. Zhao, and W. J. Kulesza, "Mutual coupling suppression between two closely spaced microstrip antennas with an asymmetrical coplanar strip wall," IEEE Antennas Wireless Propag. Lett., vol. 15, pp. 191-194, 2016.

[4] S. Gupta, Z. Briqech, A. R. Sebak, and T. A. Denidni, "MutualCoupling Reduction Using Metasurface Corrugations for $28 \mathrm{GHz}$ MIMO Applications," IEEE Antennas Wireless Propag. Lett., vol. 16, pp. 2763-2766, 2017.

[5] R. Karimian, A. Kesavan, M. Nedil, and T. A. Denidni, "Low mutual coupling 60-GHz MIMO antenna system with frequency selective surface wall," IEEE Antennas Wireless Propag. Lett., vol. 16, pp. 373-376, 2017.

[6] $\mathrm{Yu}, \mathrm{A}$. and $\mathrm{X}$. Zhang, "A novel method to improve the performance of microstrip antenna arrays using a dumbbell EBG structure," IEEE Ant. Wirel. Prop. Lett., Vol. 2, No. 1, 170-172, 2003.

[7] H.S. Farahani, M. Veysi, M. Kamyab, and A. Tadjalli, "Mutual coupling reduction in patch antenna arrays using a UC-EBG superstate," IEEE Ant. \& Wirel. Propag. Lett., Vol. 9, pp.57-59, 2010

[8] M. T. Islam, and M. S. Alam, "Compact EBG structure for alleviating mutual coupling between patch antenna array elements," Progress In Electromagnetics Research, Vol. 137, pp.425-438, 2013.

[9] F. G. Zhu, J. D. Xu, and Q. Xu, "Reduction of mutual coupling between closely packed antenna elements using defected ground structure," Electronics Letters, Vol. 45, No. 12, pp.601-602, 2012.

[10] S. Farsi, D. Schreurs, and B. Nauwelaers, "Mutual coupling reduction of planar antenna by using a simple microstrip U-section," IEEE Ant. and Wireless Propag. Letters, Vol. 11, pp.1501-1503, 2012.

[11]M. G. Alsath, M. Kanagasabai, and B. Balasubramanian, "Implementation of slotted meander line resonators for isolation enhancement in microstrip patch antenna arrays," IEEE Antennas and Wireless Propagation Letters, Vol. 12, pp.15-18, 2013.

[12] C. K. Ghosh, and S. K. Parui, "Reduction of mutual coupling between E-shaped microstrip antennas by using a simple microstrip I-section," Microwave and Optical Technology Letters, Vol. 55, No. 11, pp. 2544-2549, 2013

[13] J. OuYang, F. Yang, and Z. M. Wang, "Reduction of mutual coupling of closely spaced microstrip MIMO antennas for WLAN application," IEEE Ant. \& Wirel. Prop. Lett., Vol. 10, pp. 310-312, 2011.

[14] M. M. B. Suwailam, O. F. Siddiqui, and O. M. Ramahi, "Mutual coupling reduction between microstrip patch antennas using slottedcomplementary split-ring resonators," IEEE Antennas Wireless Propagation Letters, Vol. 9, pp.876-878, 2010

[15]M. F. Shafique, Z. Qamar, L. Riaz, R. Saleem, and S. A. Khan, "Coupling suppression in densely packed microstrip arrays using metamaterial structure," Microwave and Optical Technology Letters, Vol. 57, No. 3, pp.759-763, 2015.

[16]X. M. Yang, X. G. Liu, X. Y. Zhu, and T. J. Cui, "Reduction of mutual coupling between closely packed patch antenna using waveguide metamaterials," IEEE Antennas and Wireless Propagation Letters, Vol. 11, pp.389-391, 2012.

[17]Z. Qamar, and H. C. Park, "Compact waveguided metamaterials fo suppression of mutual coupling in microstrip array," Progress In Electromagnetic Research, Vol. 149, pp.183-192, 2014.

[18] J. Ghosh, S. Ghosal, D. Mitra, and S. R. B. Chaudhuri, "Mutual Coupling Reduction between Closely Placed Microstrip Patch Antenna Using Meander Line Resonator," Progress In Electromagnetic Res. Letters, Vol. 59, pp. 115-122, 2016.

[19]X. Yang, Y. Liu, Y.-X. Xu, and S.-Xi Gong, "Isolation Enhancement in Patch Antenna Array with Fractal UC-EBG Structure and Cross Slot," IEEE Antennas Wireless Propagation Letters, Vol. 16, pp. 2175-2178, 2017 